\title{
Factors with impact on the knowledge management practices within shared service centers
}

\author{
Violeta Mihaela DINC $\breve{A}$ \\ Bucharest University of Economic Studies, Bucharest, Romania \\ violetamihaeladinca@yahoo.fr
}

\begin{abstract}
Nowadays it has become easier and easier to reach and achieve information and a great reason for that is the fast evolution of technology. Along with these less complicated opportunities to access information there is an increasing consciousness of recognizing the ways to use it in different moments in time especially within the business environment. Successful organizations empower employees to share knowledge by rewarding them for such actions. And the organization's leaders must be role models of sharing knowledge regularly with their teams, and they should discuss openly about successes and failures. Taking all these aspects into account, in this paper various processes of knowledge management (KM) are presented from theoretical approaches to practical ones. Successful examples of KM within multiple Shared Service Centers of two multinational companies based in Bucharest, Romania are displayed in order to uncover best practices. A qualitative and in the same time a quantitative investigation were expanded and tested in these Shared Service Centers with the objective to detect the current most suitable patterns and procedures of KM in 2019 and, simultaneously, the difficulties in applying the KM methods within an organization. Information from different employees in the companies was gathered regarding the key success factors of implementing Knowledge Management in organizations (organizational culture, leadership, efficient and systematic processes, technology and strategy). The results certified that communication, along with an open professional behavior, sharing experiences and teamwork as the most important factors for boosting Knowledge Management within the organization.
\end{abstract}

Keywords: knowledge management, shared service centers, knowledge sharing

\section{Introduction}

Knowledge management represents a wide concept, used in different organizational contexts having as aim to bring a valuable improvement to the organization's goals. It is considered that the most important factors for successfully implementing knowledge management initiatives are organizational culture, leadership, efficient and systematic processes, technology and strategy (Pee \&Kankanhalli, 2016).

A culture of knowledge sharing must be enabled and aligned with the organizational objectives. The fundamental concern is that employees do not want to share information. Successful organizations empower employees to want to share intellectual information by rewarding them for such actions. And the organization's leaders must be role models of sharing information regularly with their teams, and discuss openly about successes and failures (Torres, Ferraz\& Santos-Rodriguez, 2018).

Another important factor is that the leadership must have vision, strategy and the ability to promote change management in order to emphasize how knowledge management contributes to achieving organizational objectives. There must be a team of specialists that know how to manage intellectual assets in a knowledge-based company, with the appropriate technology and infrastructure that allow for innovation. 
Furthermore, efficient and systematic processes implemented along with the latest technologies form an equally important factor for successfully implementing knowledge management (Sedighi, van Splunter, Brazier, van Beers \&Lukosch, 2016).

Therefore, the paper focuses on one essential research objective which is to examine best practices of knowledge management within a multinational company based in Bucharest Romania (which has under its command multiple Shared Service Centers) and what are the drivers and the barriers of knowledge management.

\section{Literature review}

Within the e-economy, it is essential for companies to recognize the fact that the most valued asset is knowledge and to reconsider the value of their established processes and ways of doing business.

Best practices should be shared within the company's network, and it should be understood that in the e-Economy companies that harvest and hoard their knowledge are at a competitive disadvantage. Nowadays, companies share knowledge to each other - a network approach to knowledge management, involving both internal and external parties meaning that if the outflow of knowledge is cut off, the inflow is also cut off. As a result, the key drivers in maintaining competitive success are to be open to external experts and to share ideas within a broad network (Vătămănescu, Pînzaru, Andrei \&Zbuchea, 2016).

If an organization decides to assume a certain competitive strategy, it should have the ability to profit from its learning capabilities and knowledge better than its competitors (Gast, Gundolf, Harms \&Collado, 2019). This ability depends on its knowledge management tools, the organizational structure and the management of ICTs. Thus, it is important to examine how organizations and their employees take advantage of the technological tools that can make communication more cost efficient and convenient.

The knowledge "depots"contain of all the documents with knowledge embedded in them, such as memos, reports, presentations and articles (Chhim, Somers \&Chinnam, 2017) and they are used when knowledge goes through the following phases: acquisition, creation, distribution, communication, sharing and application (Micic, 2015).

It is hard for a firm to manage well all the facets of knowledge, especially considering the commitment necessary to find the resources to solve knowledge management problems. Hence, the approaches, theories and practices that have been successful are dealt with below.

When studying the success factors in business, the human aspects become the center of interest. The most prolific personalities within the academic world agree that the intellectual assets of the employees constitute the most critical success factor in business. Usually people begin a project by focusing on the technology needs, but the key relies more in managing people and processes (Zareie\&Navimipour, 2016).

Every organization has its own definition of knowledge and its own way of gathering it, categorizing it and making it available to employees. What will work for one company will probably not work for another because organizational knowledge is subjective. The tendency to focus on technology rather than people and processes, put together with the one-size-fits-all mentality, blocks the benefits that knowledge management can bring to companies (Sedighi, van Splunter, Brazier, van Beers \&Lukosch, 2016). 
The value of knowledge creation and collaboration must be interconnected throughout an enterprise. Enterprises need to clearly define their Knowledge Management strategy, scope and requirements before selecting a solution. Also, they need to perform product evaluations in order to identify technology products that effectively meet their needs (Micic, 2015). A very important part of knowledge management - organizational learning - must be approached by increasing the volume of internal communications, by promoting cross-functional teams and, most importantly, by creating a learning community(Chhim, Somers \&Chinnam, 2017).

Ultimately, the success of the initiative is determined by a combination of the factors mentioned above and their implementation within the company. The sole activity of collecting and distributing knowledge is not enough. For a successful implementation it is very important that knowledge is easy to use in daily processes. Also, it must be accurate and up-to-date so that people can quickly contact experts for feedback and/or questions. Otherwise, if the knowledge processes required are fragmented or incomplete the initiative is endangered (Gast, Gundolf, Harms \&Collado, 2019).

Limited research attention has been given to knowledge management within shared services. Prior research has focused on the drivers and the motivations for shared service centers and their implementation issues. Nevertheless, not much is known about the challenges connected with SSCs. As an example, sharing services beyond the organizational boundaries can be seen as a dynamic process with regard to knowledge sharing practices. Undeniably, any form of outsourcing can be seen as a knowledge-based activity and a key challenge is to share efficiently and to integrate knowledge (Vătămănescu, Andrei, Nicolescu, Pînzaru\&Zbuchea, 2017).

Davenport and Prusak explain that transmitting information is not enough in order to share knowledge, because of the possibility of various meanings. Therefore, sharing knowledge within organizations is a social process in which collaborative initiatives are required and it is not enough to pair together the different parts (Davenport \&Prusak, 2010)

SSCs are always searching to add value to their service catalogue. Knowledge management services provide the perfect connection between the user community and the enterprise's optimization efforts. This link positions shared services perfectly in order to deliver results.

Knowledge management evolved from the classic and traditional training services that used to be a part of the human resources function. Although in some organizations knowledge management is a replacement for traditional training, that is not always the case. Knowledge management is connected to the constant changes that occur in technology and processes, and to the people in the company who perform their respective roles. As business progress continues to advance, knowledge management services assure that the users that are impacted are aware of the changes and are skilled enough to constitute a benefit for competitive advantage (Vătămănescu, Gazzola, Dincă\&Pezzetti, 2017).

Usually, there is a gap between the teams working on process and the technology changes through process management initiatives and the people in the organization impacted by those changes. Furthermore, along with the activities changing and becoming automated, the roles within the organization change too. Knowledge management services do not only track, communicate, and train, but also assess the impact on the roles within the organization and determine opportunities for strengthening those roles into new positions (Gast, Gundolf, Harms \&Collado, 2019). 


\section{Methodology}

For this particular case study, both qualitative and quantitative research methods were used in order to gain a better understanding of how some factors are critical for the successful application of knowledge management.

For the qualitative research part of the study, the emphasis is on the individual's interpretations of their environment andbehavior. The presentation of data lies in understanding the participants and their terms while the main purpose of qualitative research remains to study a social reality (Silverman, 2016).

The qualitative research was exploratory and involved interviewing a limited number of people - experts in the field of knowledge management within shared services centers. The qualitative research studied in depth motivations, emotions, perceptions regarding the knowledge management processes within the particular companies.

The quantitative study assumed that to evaluate the success of knowledge management,one should use the key success factors (KSFs) on the quality and quantity of the contributions to the system from the part of the employees. In this case study, the focus is on twocompanieswhich function as a shared service centersand more precisely how this particular companieswork in relation to the key success factors for knowledge management.

The choice of using a survey for the quantitative research was made to strengthen the validity of the paper. The validity was further affected by the respondents' degree of openness and their willingness to share their knowledge.

It is always a risk that personal biases might interfere the interviews however cautious the interviewer tries to be (Flick, 2018). Therefore, it is understood that, the influence of the respondents as well as own attitudes and values can always be questioned.

The survey respondents for the quantitative research are all shared service centers' employees, which validates the background literature that there is a great interest related to knowledge management implementation within the employeesof companies belonging to this business field.

For the quantitative analysis, the step was to collect primary information from different employees in the company. Primary data was collected by using fill up questions in the form of an online survey shared via e-mail at the company, and the instrument used was the questionnaire. The survey is constructed of a combination of "yes or no", grading scales and multiple-choice questions and it was created with the help of Google Forms. Before the commencement of the survey, a self-introduction followed by a brief explanation introducing the concept of knowledge management was made. The questionnaire used in the survey was structured to cover a wide range of issues.

Additionally, it was imperative for some of the employees to not be that experienced or connected with best practices of knowledge management. Since some employees were neither aware of the terminology of knowledge management, nor actively involved with some form of it, senior and junior workers were both included in the survey. There were 40 respondents in this survey, a number that served the purpose of balanced views and outcomes in the findings regarding the best practices.

The survey used for quantitative analysis consisted of 19 questions. The purpose of this survey was to handle the interpretation of the term KM and the company's key objective in KM. Another objective was to handle the aspects that come into play in KM, the openness of the culture, the processes of quality control of data, the content that is being managed, and the 
functioning of communities of practice. These aspects are assessed in their current situation. The third issue examines which communication tools are most used and how well they are appreciated.

\section{Findings}

\section{Qualitative results}

PICBE $\mid 572$

The utility of the qualitative research lies in the understanding of attitudes, opinions, beliefs, behaviours of individuals or groups of people. The method used was the interview and the investigation technique was the in-depth interview. The sampling consists of individuals meeting the conditions required by the study's objectives.

Before conducting the interview, a contact with the managers was initiated, requesting an appointment to interview them on the subject of knowledge management. This was followed up by sending an email to each of them, on the subjects that were central to the discussion during the interview, so that the respondents would be able to prepare.

During the interviews, the respondents were encouraged to talk freely within the scope of the interview guide. The interviews schedule timed out to approximately 45 minutes each, in English and the managers were inclined to participate in the research but chosed to be anonymous.

For the qualitative analysis, the focus was primarily on the top experts from the respective departments and their involvement in knowledge management, in this case there were five managers from both companies which agreed to participate. They can be described as five personalities with important roles in the department, all of them being role models for best practices in the department that they work for.

The results essentially reflect the views and opinions of these five well-informed employees. This made the answers more concrete, since the information had been obtained from the top experts. Moreover, they are the ones that implement knowledge management processes in the department they work in.

Two of the interviewees were cluster managers with a background of five / seven years working in accounting and two/ three years working as managers. The other three interviewees were: two human resources managers and one accounting expert and a team leader, all three with more than ten years experience as managers.

All five respondents were familiar with the concept of knowledge management and believed that the companies' main objective in its knowledge management strategy is the standardization of existing knowledge in the form of procedures with two respondents stating generating new knowledge inside the organization as an objective. Additionally, they think that knowledge management is included in the organizational overall strategic objectives.

As guidelines that the companies have in order to take advantage of the existing knowledge, they considered knowledge distributors, norms and the creation of virtual teams.On the other hand, all managers stated that not much of the companies' daily internal work is made through teamwork and this aspect should be further developed. The respondents believed that the use of electronic tools adds value to the daily work to a certain extent but they do not consider it a replacement for face-to-face communication. Finally, all consider that Intranet should be promoted more to work as knowledge transfers and storing places for knowledge. 


\section{Quantitative results}

The following results are based on the quantitative analysis of the responses from the survey based on the questionnaire which used either "yes or no" questions, either grading scale questionsthat provided five choices. Each choice is anchored with a descriptor ranging from strongly disagree (1) to strongly agree (5).

At the first question "Are you familiar with the concept of "knowledge management", or are there any definitions given to knowledge management initiatives internally at your workplace?", the majority of the employees from both organizations knew the term "knowledge management" or came across the term in other ways of description, with $65 \%$ of the respondents answering positively to this first question of the survey. Thus, the results to this question help to identify the overall awareness of the employees related to knowledge management.

Regarding the second question "Do the expert employees, senior\& junior colleagues share findings or inform you about the latest updates in their knowledge creation?", 85\% of the respondents gave a positive answer therefore, in general within these two particular companiesthere were little to no communication issues between colleagues, assuming the fact that the answers were not biased in any way.

When it comes to the third question "Is your team supported by the top management in sharing best practices?", $60 \%$ of the respondents stated that their team is supported by the top management in sharing best practices, $20 \%$ were neutral in their answer, while the rest $20 \%$ did not feel supported in sharing best practices.

For the fourth question "Is recording and sharing knowledge a routine or a daily habit for you as an employee?", the results demonstrate the need for strong effective and systematic processes that could provide a clear definition of the kind of knowledge that needs to be shared, documented, and managed by the employees, because only $55 \%$ agree or strongly agree with this statement.

For the fifth question "Is failure seen as an opportunity to learn at your workplace?" $50 \%$ of the respondents see it as a part of learning and growth, but it is a tight percentage rate with $20 \%$ being neutral, and $30 \%$ disagreeing with the statement.

At the sixth question "Is change accepted as part of working life?" $70 \%$ considered that change is welcomed, which highlights the fact that the two companies involved in this study put an emphasis on innovation to stay ahead of competition, with only $5 \%$ of the respondents disagreeing.

Regarding the seventh question "Are the employees cooperative and helpful when asked for information or advice?" $70 \%$ of the respondents agreed or strongly agreed which confirms the openness to change of the employees and the fact that they are more than willing to help. Only $5 \%$ of the interviewees stated that colleagues are not cooperative orhelpful when approached for information or support. We can conclude that there is a fair level of intra team communication and sharing of knowledge within both companies.

For the eighth question "Is Knowledge sharing seen as strength and knowledge hoarding as a weakness?"an overwhelming $90 \%$ of the respondents agreed or strongly agreed that knowledge sharing is a strength, while knowledge hoarding can be considered a weakness.

When it comes to the ninth question "Is good knowledge management behavior like sharing, reusing knowledge actively promoted on a day-to-day basis?"'only 55\% of the employees involved in this research thought that there is some reusing of knowledge actively and this 
activity is promoted on a day-to-day basis as an active routine behavior,but there much room to improve when dealing with encouraging knowledge sharing actions for both companies.

With respect to the tenth question "Is knowledge sharing across departmental boundaries actively encouraged?"the results are even more discouraging as almost $60 \%$ of the respondents pointed out that knowledge sharing across departmental boundaries is not encouraged enough.

Concerning the eleventh question "Are training and development programs in knowledge

PICBE | 574 management undertaken from the point of recruitment?" $50 \%$ of the employees regard the recruitment procedure out-dated especially on the issue of training and that knowledge management skills are not enough included within this stage of the employees' instruction.

With reference to the twelfth question "In the day-to-day working environment, is it easy to find the right information?"the responses impliedfor $65 \%$ of the employees that it is relatively easy to find the right information by a fair amount of navigation in the day-to-day work environment.

On the topic of the thirteenth question "When a team completes a task, do they document what has been learned?"the answers were almost equally distributed with $50 \%$ of the respondents stating that on completion of a task by the team, the lessons learnt are not effectively distilled for documentation.

Referring to the fourteenth question "Do you know who are the go-to experts for different domains of key knowledge?" $75 \%$ of the employees know who are the go-to experts for different domains of key knowledge.

For the fifteenth question "How is your or other individuals' knowledge shared internally in the company?" "face-to-face" is ranked first with an 80 percentage rate followed by e-mail with a percentage rate of $65 \%$. Several respondents also recognized the contributions of group sessions $(35 \%)$ and courses $(30 \%)$, but the Intranet and databases are barely recognized as technologies used forknowledge sharing $(10 \%)$. This supports the fact that these practices are not promoted enough within the company and, therefore the employees usually do not use them.

Regarding the sixteenth question "How much group work do you conduct in your daily work?", the overall results (almost 60\%) lead to the conclusion that not much group work is conducted, and that this is certainly not a daily occurrence.

As to the seventeenth question "In what way do you think electronic tools are adding value to individual and overall performance?" $65 \%$ of the respondents mentioned increased performance and $25 \%$ thought that electronic tools are providing better work access.

With attention to the eighteenth question "To what extent do you think electronic tools can replace face-to-face communication?" $70 \%$ of the respondents thought that even though IT Tools give opportunities to increase interaction both internal and with external partners in the end, the company is very dependent on its personal communication skills.According to the answers, there was a strong preference for face-to-face communication, which remains essential in the two shared service centers included in this research.

Finnally on the topic of the last (nineteenth) question "Have any of your virtual work relations failed? If so, what were the major causes?"half of the respondents believed that communication issues constitute a key factor in failed virtual relationships, followed by trust issues with $20 \%$ and knowledge skill issues chosen by $15 \%$. 


\section{Conclusion}

The overall conclusion of the research could be resumed that the answers at our quantitative survey favored communication, along with professional behavior, knowledge skills, experience sharing and also teamwork as the most important factors for knowledge management well implemented. An open organization is less sensitive to individual cultural aspects and allows for internal and external communication.

PICBE | 575

It was concluded that knowledge sharing among departments is not actively encouraged so there is a need for more active analysis and dissemination. This can be achieved either through intelligent agents, or a team of individuals analyzing the lessons learned, by collecting, examining and disseminating knowledge.

Furthermore, the internet and the intranet have not made a significant contribution to make the companies more competitive and there are no clear measures on this subject.

The responses also indicated the need to institute new measures and a change in the perception to the processes carried out in the company. Furthermore, the analysis of the different results lead to the conclusion that increased openness, transparent policies, investments in ICTs and structural changes are required. There is a high level of need and desire for strategic knowledge management but only a low level of real implementation actually exists.

\section{References}

Chhim, P.P., Somers, T.M., \&Chinnam, R.B. (2017) Knowledge reuse through electronic knowledge repositories: a multi theoretical study, Journal of Knowledge Management, Vol. 21, No.4, pp.741-764

Davenport, T.H.,\&Prusak, L. (2010)Working Knowledge: How organizations manage what they know, Boston, MA: Harvard Business School Press

Flick, U. (2018) An introduction to qualitative research, London: Sage Publications

Gast, J., Gundolf, K., Harms, R., \&Collado, E.M. (2019) Knowledge management and coopetition: How do cooperating competitors balance the needs to share and protect their knowledge?,Industrial Marketing Management, Volume 77, February 2019, pp. 65-74

Micic, R. (2015) Leadership role in certain phases of knowledge management processes, Ekonomika, Vol. 61, Issue 4, pp. 47-56

Pee, L.G. \&Kankanhalli, A. (2016) Interactions among factors influencing knowledge management in public-sector organizations: A resource-based view, Government Information Quarterly, Vol. 33, Issue 1, pp.188-199

Sedighi, M., van Splunter, S., Brazier, F., van Beers, C., \&Lukosch, S. (2016) Exploration of multi-layered knowledge sharing participation: the roles of perceived benefits and costs, Journal of Knowledge Management, Vol. 20, No.6, pp. 1247-1267

Silverman, D. (2016) Qualitative Research, London: Sage Publications

Torres, A.I., Ferraz, S. \& Santos-Rodriguez, H. (2018) The impact of knowledge management factors in organizational sustainable competitive advantage, Journal of Intellectual Capital, Vol. 19, No.2, pp. 453-472

Vătămănescu, E.-M., Andrei, A.G., Nicolescu, L., Pînzaru, F., \&Zbuchea, A. (2017).The Influence of Competitiveness on SMEs Internationalization Effectiveness.Online versus Offline Business Networking.Information Systems Management, Vol. 34, No.3, pp. 205219 
Vătămănescu, E.-M., Gazzola, P., Dincă, V.M., \&Pezzetti, R. (2017).Mapping Entrepreneurs' Orientation towards Sustainability in Interaction versus Network Marketing Practices. Sustainability, 9(9), 1580

Vătămănescu, E.-M., Pînzaru, F., Andrei, A.G., \&Zbuchea, A. (2016).Investigating SMEs sustainability with partial least squares structural equation modeling. Transformations in Business \& Economics (TIBE), 15(3), 259-273

PICBE $\mid 576$

Zareie, B., \&Navimipour, N.J. (2016) The impact of electronic environmental knowledge on the environmental behaviors of people, Computers in Human Behavior, Vol. 59, June 2016, pp. 1-8 